\title{
Renal Synovial Sarcoma- A Rare Primary Malignancy
}

\author{
Agrawal V and Khurana CS* \\ Department of Surgery, University College of Medical \\ Sciences \& Guru Teg Bahadur Hospital, India \\ *Corresponding author: Khurana CS, Department \\ of Surgery, University College of Medical Sciences \& \\ Guru Teg Bahadur Hospital, Dilshad Garden, New \\ Delhi-110095, India
}

Received: September 17, 2019; Accepted: October 14, 2019; Published: October 21, 2019

\section{Abstract \\ Synovial sarcoma (SS) is a tumour of the soft tissues with a unique chromosomal translocation $\mathrm{t}(\mathrm{X} ; 18)(\mathrm{p} 11.2 ; \mathrm{q} 11.2)$ detected by polymerase chain} reaction in tissue homogenates.

A 36 years old woman, with complaints of pain and lump in left flank was found to have a large lump occupying the left flank, left hypochondrium and the umbilical region, which was bimanually palpable and did not cross the midline. Investigations were suggestive of left RCC for which patient was operated. Intraoperatively, a tumour mass was seen replacing the whole kidney with involvement of left adrenal gland. Histopathology of the specimen revealed primary synovial sarcoma of left kidney.

Keywords: Primary synovial sarcoma kidney

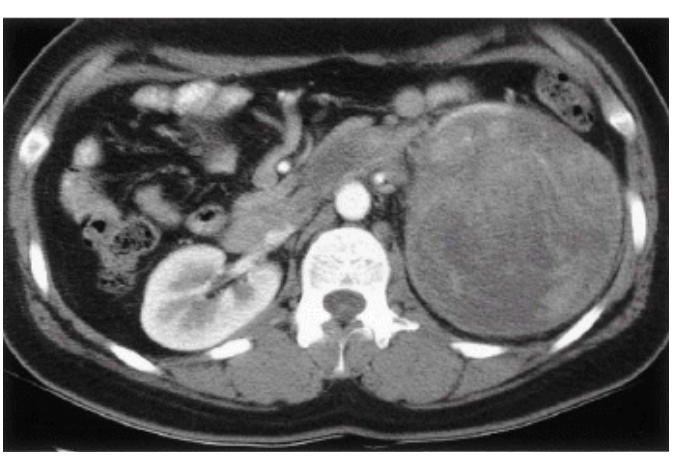

Figure 1: Large heterogeneously enhancing exophytic mass lesion involving left kidney.

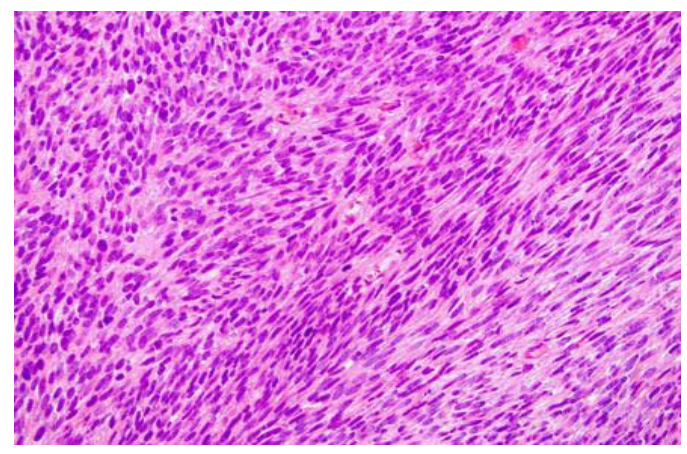

Figure 2: Spindle cells with nuclear atypia (monophasic type).

Microscopy revealed monophasic type of synovial sarcoma with 12-15 mitosis per 10 high power fields. Resected margins were free from tumour and there was no lymphovascular invasion.

\section{Discussion}

Primary Synovial Sarcoma (PSS) of kidney is a rare tumour first reported by Faria et al in 1999 [1]. Until date, 114 cases of PSS have been reported worldwide [2]. It occurs in two forms: Biphasic and Monophasic. The primary biphasic synovial sarcoma contains both glandular elements and spindle epithelial cells. The primary 
monophasic synovial sarcoma is composed of only spindle cells. The monophasic variant cannot be diagnosed by histology in isolation and requires confirmation by molecular analysis. The characteristic chromosomal translocation seen in primary synovial sarcoma of kidney is $\mathrm{t}(\mathrm{X} ; 18)(\mathrm{p} 11.2 ; \mathrm{q} 11.2)$. This translocation results in fusion of SYT gene located on chromosome 18 with SSX gene located on chromosome X [3].

The most common presenting complaints of a patient with primary synovial sarcoma of the kidney are flank pain and/or haematuria. No clinical feature or imaging modality is diagnostic for Primary Synovial Sarcoma of the kidney. The CT scan usually reveals a heterogeneously enhancing renal mass and the confirmation of diagnosis is by molecular and cytogenetic analysis. Rarely, it can present as an advanced stage with caval thrombus and/or metastasis.

There are no established guidelines regarding management of this tumour owing to the limited number of cases reported. Surgery in the form of radical nephrectomy is considered the treatment of choice. The effectiveness of chemotherapy is yet to be proven but SS may be sensitive to high doses of Ifosamide-based regimens. Park et al., [4] reported complete remission of metastatic lung lesion using Ifosamide and doxorubicin during the four-week course.

\section{Conclusion}

This rare tumour is likely to be confused with other spindle cell tumours of the kidney. An accurate diagnosis, including cytogenetic and molecular studies is imperative. Primary SS should be included in differential diagnosis when dealing with the spindle cell tumours of kidney.

\section{References}

1. FARIA P. Primary synovial sarcoma of the kidney: a molecular subset of socalled embryonal renal sarcoma. Mod Pathol. 1999; 12: 94A.

2. El Chediak A, Mukherji D, Temraz S, Nassif S, Sinno S, Mahfouz R, et al. Primary synovial sarcoma of the kidney: a case report of complete pathological response at a Lebanese tertiary care center. BMC Urol. 2018; 18: 40.

3. Skytting B, Nilsson G, Brodin B, Xie Y, Lundeberg J, Uhlén M, et al. A novel fusion gene, SYT-SSX4, in synovial sarcoma. J Natl Cancer Inst. 1999; 91: 974-975.

4. Park SJ, Kim HK, Kim CK, Park SK, Go ES, Kim ME, et al. A case of renal synovial sarcoma: complete remission was induced by chemotherapy with doxorubicin and ifosfamide. Korean J Intern Med. 2004; 19: 62-65.
Austin J Surg - Volume 6 Issue $21-2019$

ISSN : 2381-9030 | www.austinpublishing group.com

Khurana et al. (C) All rights are reserved
Citation: Agrawal V and Khurana CS. Renal Synovial Sarcoma- A Rare Primary Malignancy. Austin J Surg. 2019; 6(21): 1218 